\title{
Predictive regression equation and nomogram of peak expiratory flow rate in healthy school going children of Kolhapur, Maharashtra, India
}

\author{
Sachin Verma ${ }^{1}$, *Suhas Kulkarni ${ }^{2}$, Neha Verma ${ }^{3}$, Bhuwan Kumar Singh ${ }^{1}$, Jaiprakash Jaiswal ${ }^{1}$ \\ Sri Lanka Journal of Child Health, 2022; 51(1): 8-13 \\ DOI: http://dx.doi.org/10.4038/sljch.v51i1.9987
}

\begin{abstract}
Background: Peak expiratory flow rate (PEFR) estimation plays a vital role in the evaluation and management of asthmatic children.
\end{abstract}

Objectives: To assess the correlation of PEFR with anthropometry and obtain the normal reference value for the paediatric group in Karveer Taluka, Kolhapur, Maharashtra, India

Method: A cross-sectional study was conducted on 1200 healthy school going children aged 10-16 years. Anthropometric parameters were measured. Peak Flow Master Breathe-O-Meter was used to determine PEFR. PEFR was measured thrice for each student and the mean value was noted in the proforma. Correlation of PEFR with height and weight was determined by the Spearman-RankCorrelation test. A simple linear regression was derived for PEFR prediction in R software (version 3.6.1).

Results: Mean heights and weights of the boys were $140 \pm 10.8 \mathrm{~cm}$ and $37.06 \pm 10.56 \mathrm{~kg}$ respectively. Overall mean PEFRs of boys and girls were $362.16 \pm 89.8 \mathrm{~L} / \mathrm{min}$ and $351.3 \pm 79.78 \mathrm{~L} / \mathrm{min}$ respectively. In both boys and girls, PEFR was positively correlated with height $(\mathrm{r}=0.9104$ and $\mathrm{r}=0.875$ respectively) and weight $(\mathrm{r}=0.7956$ and $\mathrm{r}=0.7533$ respectively). A feasible regression equation and nomograms were derived to predict PEFR.

Conclusions: The derived regression equation and nomogram can be used for PEFR prediction in 10-

\footnotetext{
${ }_{1}^{1}$ Junior Resident, ${ }^{2}$ Associate professor, Department of Paediatrics, ${ }^{3}$ Senior Resident, Department of Obstetrics and Gynaecology, D Y Patil Medical College, Kolhapur, Maharashtra, India

*Correspondence: kulkarnisuhas34@gmail.com$$
\text { (iD) }
$$$$
\text { https//orcid.org/ } 0000000208729846
$$

(Received on 08 December 2020: Accepted after revision on 08 February 2021)

The authors declare that there are no conflicts of interest

Personal funding was used for the project.

Open Access Article published under the Creative

Commons Attribution CC-BY (c) (i) License
16 year old children with symptoms of obstructive airway disorders considering the obtained mean PEFR values as reference values for Karveer Taluka, Kolhapur, Maharashtra, India.

(Key words: Anthropometric parameters, Asthma, Nomogram, Peak expiratory flow rate)

\section{Introduction}

Asthma is the commonest chronic respiratory disorder in children leading to hospitalization ${ }^{1}$. Globally, the prevalence of asthma ranges from 1$18 \%$ of the population in various countries ${ }^{2}$. In India, the prevalence of asthma is between 10 and $15 \%$ in children aged 5-11 years ${ }^{3}$. Pulmonary functions are associated with climatic, geographical, nutritional, anthropometric and socio-economic conditions of India ${ }^{4}$. Beside these conditions, altitude contributes widely in the determination of pulmonary function ${ }^{5}$. Therefore, assessment of pulmonary function in the paediatric population is very essential.

The peak expiratory flow rate (PEFR), measured by the peak flow meter, is one of the pulmonary function tests that helps in assessing obstructive pulmonary disorders, especially asthma. Peak flow meter also plays a vital role in improving the quality of life of asthmatic patients by accurate assessment and anticipates the attack $^{6}$. In addition, PEFR is affected by anthropometry (age, gender, height and weight), residential area (urban and rural) and it also varies from region to region ${ }^{7}$. Furthermore, the results obtained from PEF assessments are interpretable only by the 'reference values' of the population to which the individual belongs ${ }^{7}$. Therefore, it is mandatory to have the reference values for each region.

\section{Objectives}

To assess the correlation of PEFR with anthropometry and to obtain the normal reference values for the paediatric group in Karveer Taluka, Kolhapur, Maharashtra, India.

\section{Method}

The cross-sectional study was carried out from August 2017-July 2019 on healthy school going children.

The sample size was calculated using the standard formula- 
$\boldsymbol{n}=\frac{\left[Z_{\alpha}+Z_{\beta}\right]^{2}}{C}+3$

where, $\mathrm{C}=0.5 * \ln \left[\frac{(1+r)}{(1-r)}\right], \alpha=0.05$ (Threshold probability for rejecting the null hypothesis. Type I error rate), $Z_{\alpha}=1.96$ (The standard normal deviate for $\alpha$ ), $\beta=0.20$ (Probability of failing to reject the null hypothesis under the alternative hypothesis. Type II error rate), $Z_{\beta}=0.84$ (The standard normal deviate for $\beta$ ), $r=0.10$ (The expected correlation coefficient.)

The minimum sample size obtained was 1047 .

One thousand two hundred healthy students from 107 schools of Karveer Taluka, Kolhapur, who gave written consent and were aged between 10-16 years (100 students each for each age group from rural area and 100 students each for each age group from urban area) were selected by stratified sampling.

Students having acute respiratory infections within 7 days of the study, family history of asthma, major medical illness, recurrent cough or chest infections or chest deformity, with rhonchi or wheeze on auscultation or other findings suggestive of chronic illness, a person taking bronchodilator metered dose inhaler (MDI) in the family, malnourished (according to IAP standards criteria), not belonging to the desired age group and who did not give written informed consent were excluded.

A self-designed structured questionnaire was used to collect demographic and clinical history. The anthropometric measurements, such as height and weight, were measured as described by Manjunath CB et $a .^{7}$ Peak Flow Master Breathe-O-Meter (CIPLA) was used to measure PEFR. Method of carrying out the test was demonstrated to all the students. Post-demonstration, one after the other all students were asked to take deep breaths and blow them out as hard as possible, in short sharp blasts through the disposable mouthpieces of peak flow meters in standing position. The used disposable mouthpieces were disposed of with care and new disposable mouthpieces were given to each student.
PEFR was measured thrice for each student and the mean values were noted in the proforma to eliminate technical error. Measurement of flow rate was carried out by a single observer in order eliminate errors.

Ethical issues: Approval was obtained from the Institutional Ethics Committee, D Y Patil Medical College, Kolhapur, India (No. DMCK/151/2018). Permission was obtained from school authorities. Aim of study was explained to all parents and students of higher classes. Written consent was obtained from students of higher classes and from parents of younger students prior to study.

Statistical analysis: Data were analysed in R software (version 3.6.1). Quantitative variables were expressed as means and standard deviations. Correlations of PEFR with height and weight were analysed using Pearson correlation coefficient. A simple linear regression was done for PEFR prediction in each parameter. Multivariate regression was performed for PEFR prediction using all the parameters.

\section{Results}

There were no dropouts during the study giving a $100 \%$ response rate. Gender distribution was $50 \%$ girls and $50 \%$ boys; $50 \%$ of both boys $(n=300)$ and girls $(n=300)$ were the residents of urban areas.

The mean heights, weights and PEFRs of the boys were $140 \pm 10.8 \mathrm{~cm}, 37.06 \pm 10.56 \mathrm{~kg}$ and $362.16 \pm 89.8$ $\mathrm{L} / \mathrm{min}$, respectively.

The mean heights, weights and PEFRs of girls were $138.3 \pm 10.6 \mathrm{~cm}, \quad 36.44 \pm 6.29 \mathrm{~kg}$ and $351.3 \pm 79.78$ $\mathrm{L} / \mathrm{min}$, respectively.

Distribution of students and their mean PEFR with respect to age is given in Table 1. PEFR increased with increase in age in both boys and girls except in girls aged 15-16 years (Table 1). Since age was the continuous variable, the correlation between PEFR and age could not be calculated.

Regression equation based on age was found to beBoys- Regression equation $\mathrm{y}=241.75+3.41 \mathrm{x}$ Girls - Regression equation y $=258.92+26.41 \mathrm{x}$

Table 1: Distribution of students and their mean PEFR with respect to age

\begin{tabular}{|c|c|c|c|c|}
\hline \multirow{2}{*}{ Age (years) } & \multicolumn{2}{|c|}{ Boys } & \multicolumn{2}{c|}{ Girls } \\
\cline { 2 - 5 } & Frequency (n) & Mean \pm SD & Frequency (n) & Mean \pm SD \\
\hline $10-11$ & 100 & $283.4 \pm 44.05$ & 100 & $264.8 \pm 47.19$ \\
\hline $11-12$ & 100 & $355 \pm 70.18$ & 100 & $341.29 \pm 59.09$ \\
\hline $12-13$ & 100 & $355 \pm 70.18$ & 100 & $341.29 \pm 59.09$ \\
\hline $13-14$ & 100 & $389 \pm 71.49$ & 100 & $386.6 \pm 62.66$ \\
\hline $14-15$ & 100 & $424.8 \pm 76.47$ & 100 & $407.4 \pm 57.11$ \\
\hline $15-16$ & 100 & $434.4 \pm 66.95$ & 100 & $388.1 \pm 55.98$ \\
\hline
\end{tabular}

Distribution of students and their mean PEFRs with respect to height is given in Table 2. PEFR increased with increase in height in boys (Table 2). Pearson correlation coefficient revealed that height and PEFR were positively correlated in both boys and girls $(r=0.9109 ; r=0.8263$ respectively). By simple linear regression model, the regression equation based on height was found to be: Boys- Regression equation $\mathrm{y}=-611.5638+6.9552 \times$ Girls Regression equation $\mathrm{y}=-506.3226+6.2048 \mathrm{x}$ 
Table 2: Distribution of students and their mean PEFR with respect to height

\begin{tabular}{|c|c|c|c|c|}
\hline \multirow{2}{*}{ Height (cm) } & \multicolumn{2}{|c|}{ Boys } & \multicolumn{2}{c|}{ Girls } \\
\cline { 2 - 5 } & Frequency (n) & Mean \pm SD & Frequency (n) & Mean \pm SD \\
\hline $111-120$ & 02 & $220 \pm 63.41$ & 11 & $205.45 \pm 6.12$ \\
\hline $121-130$ & 153 & $266.01 \pm 90.68$ & 150 & $268.46 \pm 80.87$ \\
\hline $131-140$ & 195 & $328.92 \pm 89.54$ & 213 & $334.92 \pm 82.71$ \\
\hline $141-150$ & 120 & $415 \pm 90.38$ & 137 & $414.59 \pm 80.13$ \\
\hline $151-160$ & 93 & $465.05 \pm 89.88$ & 62 & $466.77 \pm 76.83$ \\
\hline $161-170$ & 37 & $512.7 \pm 90.12$ & 27 & $425.33 \pm 77.25$ \\
\hline
\end{tabular}

Distribution of students and their mean PEFR with respect to weight is given in Table 3. PEFR increased with increase in weight in both boys and girls (table 3). Pearson correlation coefficient revealed that in both boys and girls, weight and PEFR were positively correlated $(r=0.7354$; $\mathrm{r}=0.7417$ respectively). By simple linear regression model, the regression equation based on weight was found to be-

Boys- Regression equation $\mathrm{y}=27.5031+9.0299 \mathrm{x}$

Girls - Regression equation $\mathrm{y}=8.5756+9.4052 \mathrm{x}$

Table 3: Distribution of students and their mean PEFR with respect to weight

\begin{tabular}{|c|c|c|c|c|}
\hline \multirow{2}{*}{ Weight (kg) } & \multicolumn{2}{|c|}{ Boys } & \multicolumn{2}{c|}{ Girls } \\
\cline { 2 - 5 } & Frequency (n) & Mean \pm SD & Frequency (n) & Mean \pm SD \\
\hline $21-30$ & 98 & $277.27 \pm 83.05$ & 164 & $268.86 \pm 84.58$ \\
\hline $31-40$ & 354 & $346.37 \pm 86.76$ & 262 & $346.20 \pm 84.77$ \\
\hline $41-50$ & 138 & $446.67 \pm 84.99$ & 146 & $427.46 \pm 84.33$ \\
\hline $51-60$ & 10 & $495.93 \pm 86.14$ & 28 & $501.82 \pm 87.31$ \\
\hline
\end{tabular}

Regression model based on height is comparatively better to estimate PEFR in both boys and girls $\left(\mathrm{R}^{2}=\right.$ $0.8135 ; \mathrm{R}^{2}=0.682$ respectively).

By multivariate regression, the equations for prediction of PEFR in boys and girls were found to be-
Boys- PEFR $=-506.37+2.65($ Age $)+2.58($ Weight $)$ +5.46 (Height)

Girls- PEFR $=-473.49-5.50$ (Age) +4.53 (Weight $)$ +4.91 (Height)

PEFR nomograms at various ages, heights and weights of boys and girls is shown Figure 1 .

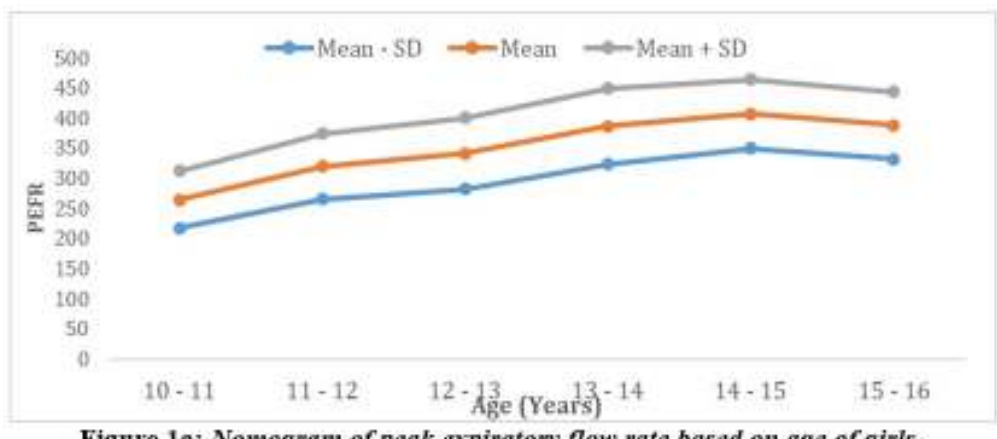

Figure 1a: Nomogram of peak expiratory flow rate based on age of girls

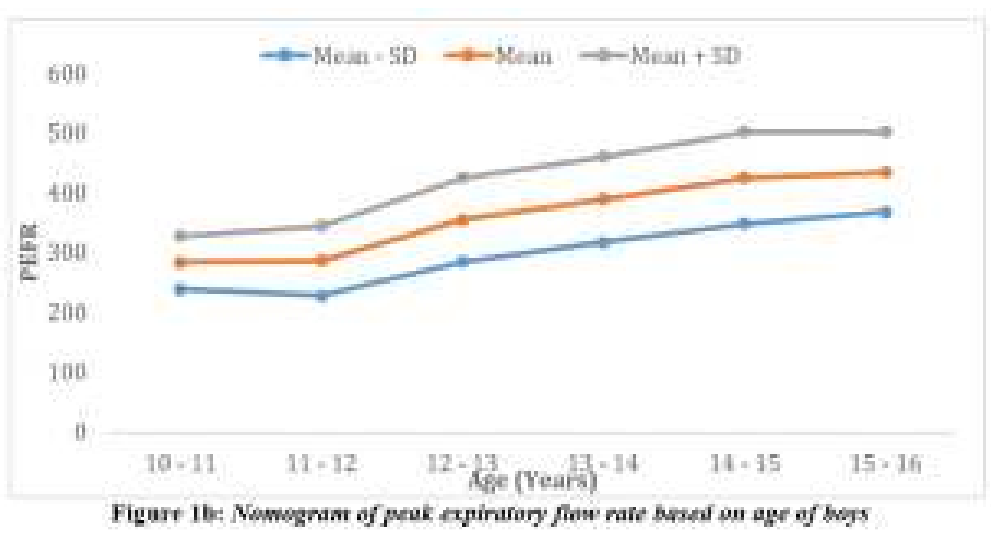




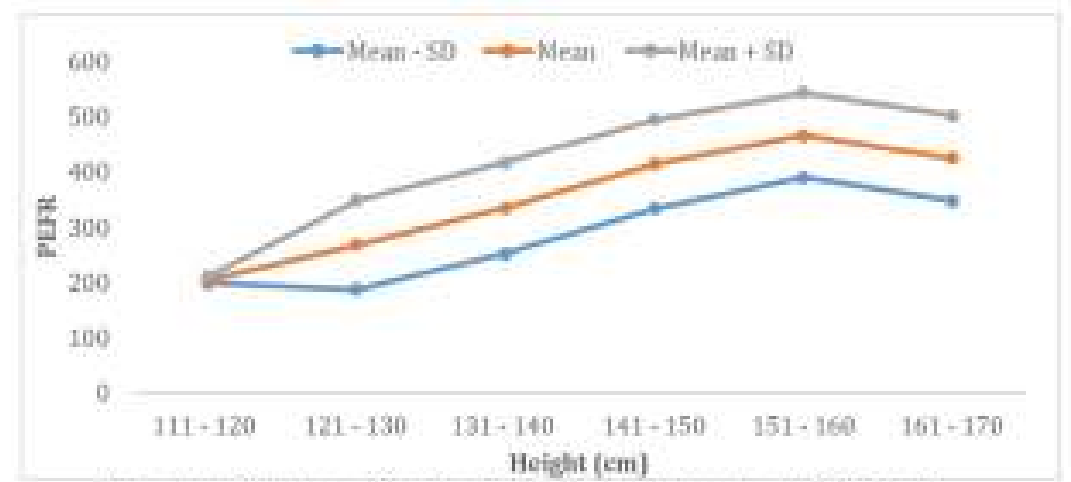

Figure te; Nompgraw of prak expinatory Ros natc besed on herigh for gints

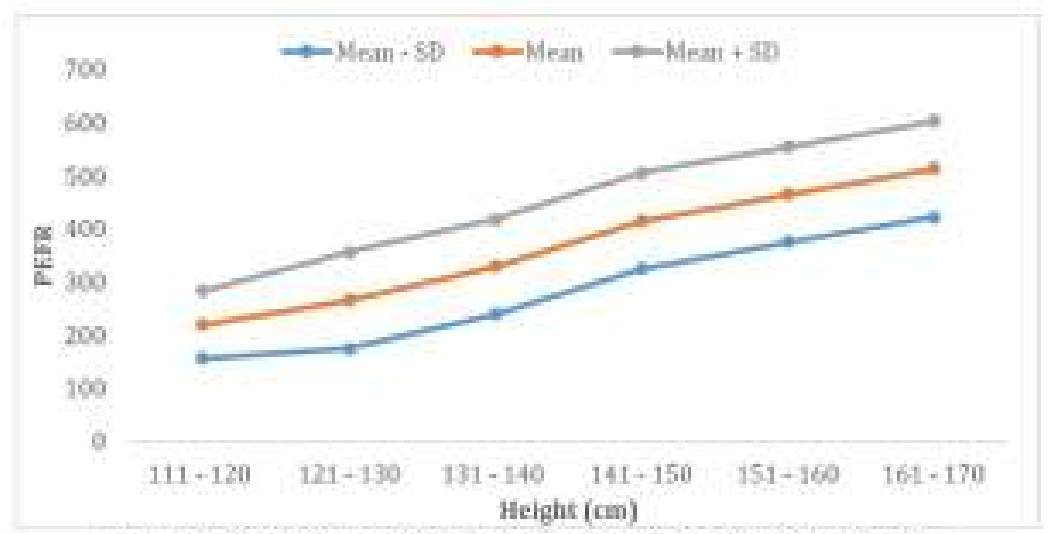

Figure 1it: Nomograw of peak equinatory fow nute begsed on height for bogs

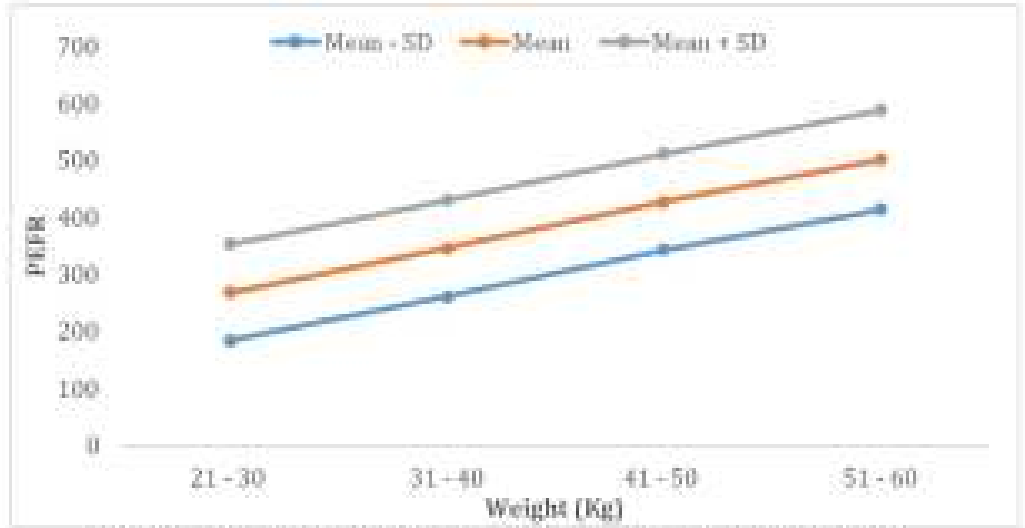

Yigure 1e: Nowognaw of peak eqpindtony flow rate kased an weight for gotls

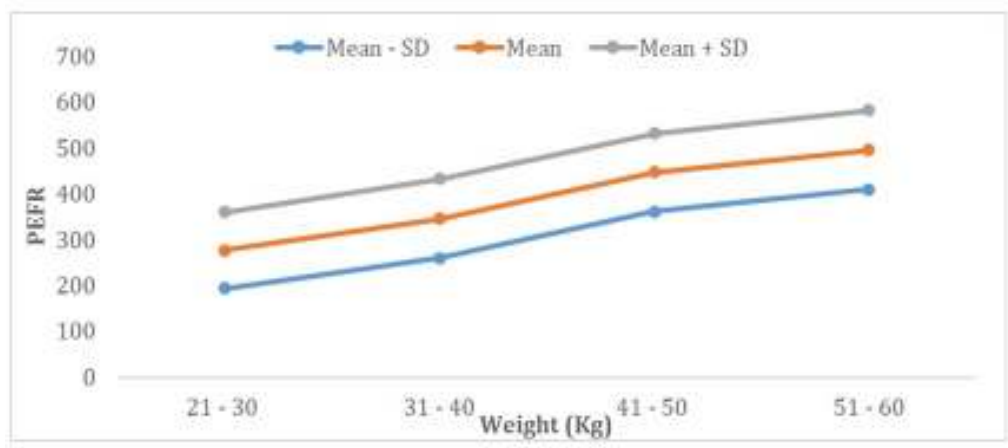

Figure 1f: Nomogram of peak expiratory flow rate based on weight for boys

\section{Discussion}

Respiratory problems are the commonest cause of morbidity and mortality in children in both developed as well as developing countries. Globally, PEFR measurement has gained huge importance for assessment of patients with restrictive and 
obstructive pulmonary disorders, particularly after development of simple portable peak flowmeter instruments. In asthmatic patients, such pulmonary function tests are very helpful in treating them by assessing disturbance and obstruction in exchange of gases, their reactions towards the inhaled chemicals and allergens and the therapeutic agents ${ }^{7}$. The unawareness of the degree of pulmonary obstruction is the major contributor to delay in the initiation of treatment. Severity of episodes, especially in children with difficulty in asthma control, remains unrecognized. This leads to death even before they consult doctors.

The study is demographically comparable with similar studies ${ }^{7-9}$. PEFR values in boys were slightly higher than girls concerning age, height and weight which can be attributed to the physical or physiological differences between them. Unlike the PEFR values of boys, the reduction in PEFR value of girls with higher age and height was evident. However, this can be due to the various physiological changes during puberty. Fascinatingly, there was no reduction in PEFR of girls concerning the higher weight. Moreover, the PEFR values of girls who weighed between 51-60 $\mathrm{kg}$ were higher than that of boys of the same weight group. However, the reason of this disparity is not clear.

PEFR depends on the individual's growth which is obvious by the increase in PEFR with increase in anthropometry and their positive correlation ${ }^{10-16}$. Mean PEFR values based on age, height and weight were high compared to studies done in northern and southern parts of India ${ }^{9,16,20}$. This can be attributed to diversities in culture, region, altitude, class, lifestyle, diet and socio-economic status ${ }^{5,17-19}$.

The regression equation derived in the study assesses PEFR based on the anthropometry such as height and weight. Ability of this equation to assess the risk of asthma or any respiratory disorders by estimating PEFR with minimum requirement of cooperation and the basic characteristics may help in early and proper treatment where the risk of mortality of respiratory disorder is predominant. Since height was highly correlated with PEFR, the regression model based on height is a better estimate of PEFR in both boys and girls ${ }^{19}$.

While there are studies that have assessed the reference values of PEFR, correlation between PEFR and anthropometry and to obtain reference values of PEFR in different parts of the world, this is the first study to report the same on the paediatric group of Karveer Taluka, Kolhapur using the randomly selected representative sample. Since mean PEFR values and the regression equation were obtained from healthy children of Karveer Taluka, it can be considered as reference to estimate PEFR for the same population.

However, the study had limitations since the body mass index (BMI), nutritional state and residential area were not determined and considered for PEFR prediction. Further similar studies taking the above limitations into consideration could help in better prediction of PEFR.

\section{Conclusions}

The derived regression equation and the nomogram can be used to estimate PEFR among the children of Kolhapur considering the obtained mean PEFR values as reference.

\section{Acknowledgments}

We thank the colleagues of the Department of Paediatrics and Dr. D Y Patil Hospital \& Research Institute for data collection and conducting study.

\section{References}

1. Diette GB, Markson L, Skinner EA, Nguyen TT, Algatt-Bergstrom P, Wu AW. Nocturnal asthma in children affects school attendance, school performance, and parents' work attendance. Archives of Pediatrics and Adolescent Medicine 2000; 154: 923-8.

https://doi.org/10.1001/archpedi.154.9.923 PMid: 10980797

2. Saharan S, Lodha R, Kabra SK. Management of status asthmaticus in children. Indian Journal of Pediatrics 2010; 77: 1417-23. https://doi.org/10.1007/s12098-010-01898

PMid: 20824393

3. World Health Organization Media Centre. Bronchial asthma. Factsheet N206. [Internet] Available from: https://www.who.int/news-room/factsheets/detail/asthma (Accessed on May 18, 2019).

4. Raju PS, Prasad KV, Ramana YV, Murthy KJ. Pulmonary function tests in Indian girls- prediction equations. Indian Journal of Pediatrics 2004; 71: 893-7. https://doi.org/10.1007/BF02830828 PMid: 15531830

5. Gupta S, Mittal S, Kumar A, Singh KD. Peak expiratory flow rate of healthy school children living at high altitude. North American Journal of Medical Sciences 2013; 5: 422-6. 
https://doi.org/10.4103/1947-2714.115781

PMid: 24020052 PMCid: PMC3759070

6. López-Viña A, del Castillo-Arevalo E. Influence of peak expiratory flow monitoring on an asthma self-management education programme. Respiratory Medicine 2000; 94: 760-6.

https://doi.org/10.1053/rmed.2000.0815

PMid: 10955751

7. Manjunath CB, Kotinatot SC, Babu M. Peak expiratory flow rate in healthy rural school going children (5-16 years) of Bellur region for construction of nomogram. Journal of Clinical and Diagnostic Research 2013; 7: 2844-6.

8. Mohammadzadeh I, Gharagozlou M, Fatemi SA. Normal values of peak expiratory flow rate in children from the town of Babol, Iran. Iranian Journal of Allergy, Asthma and Immunology 2006; 5: 195-8.

9. Mittal S, Gupta S, Kumar A, Singh KD. Regression equations for peak expiratory flow in healthy children aged 7 to 14 years from Punjab, India. Lung India 2013; 30: 183-6.

https://doi.org/10.4103/0970-2113.116245

PMid: 24049251 PMCid: PMC3775196

10. Radziavicius FR, Martins LC, Radziavicius CC, Valenti VE, Siqueira AA, de Souza $\mathrm{CG}$, et al. Peak expiratory flow values are higher in older and taller healthy male children: an observational study. Clinical and Investigative Medicine 2010; 33: E928.

https://doi.org/10.25011/cim.v33i2.12347 PMid: 20370996

11. Wun YT, Chan MS, Wong NM, Kong AY, Lam TP. A curvilinear nomogram of peak expiratory flow rate for the young. Journal of Asthma 2013; 50: 39-44. https://doi.org/10.3109/02770903.2012.74 3152

PMid: 23174006

12. Pulickal AS, Fernandez GV. Peak expiratory flow rate in healthy rural south Indian school children predicted from body height. Indian Journal of Public Health 2007; 51: 117-9.

13. Taksande A, Jain M, Vilhekar K, Chaturvedi P. Peak expiratory flow rate of rural school children from Wardha district,
Maharashtra in India. World Journal of Pediatrics 2008; 4: 211-4. https://doi.org/10.1007/s12519-008-00391

PMid: 18822931

14. Ahmed M, Gavhane J, Goel S. Age specific peak expiratory flow nomogram in children. Indian Journal of Pediatrics 2017; 84: 271-5. https://doi.org/10.1007/s12098-017-22971

PMid: 28160155

15. John JM, Paulose A. Normal peak expiratory flow rate and nomogram for children (8-12 years). Indian Journal of Pediatrics 2017; 84: 477-8. https://doi.org/10.1007/s12098-017-23135 PMid: 28229370

16. Sharma M, Sharma RB, Choudhary R. Peak expiratory flow rates in children of western Rajasthan, 7-14 years of age. Pakistan Journal of Physiology 2012; 8: $45-8$.

17. Das B, Ghosh T, Gangopadhyay S. Peak expiratory flow rate among child labourers in West Bengal, India. Indian Pediatrics 2011; 48: 487-8.

18. Ostrowski S, Barud W. Factors influencing lung function are the predicted values for spirometry reliable enough. Journal of Physiology and Pharmacology 2006; 57 (Suppl 4): 263-71.

19. Aivazis V, Hatzimichail A, Stavridis J, Bourli E, Konstantinidis TH, Katsougiannopoulos V. Growth and other factors affecting peak expiratory flow in Greek children. Minerva Pediatrics 2005; 57: 83-9.

20. John JM. Paediatric peak expiratory flow rate nomograms for Ernakulam district. Indian Journal of Allergy, Asthma, and Immunology 2017; 31: 83-6. https://doi.org/10.4103/ijaai.ijaai_6_17 